\title{
A MERENCÓRIA LUZ DO ESTADO
}

Carlos Alberto Dória

Sociólogo, Consultor do Projeto Revisão Institucional e Organizacional do Ministério da Cultura

\begin{abstract}
Resumo: O artigo trata da relação sempre mutável do Estado com o chamado "campo da cultura". Focalizando inicialmente a necessidade do Estado pós-iluminista de intervir no campo de formação da cidadania, como demanda formulada ante sua missão pedagógica, o autor passa para o plano da história brasileira mostrando como, pelos seguidos textos constitucionais, foi o Estado ampliando a definição da esfera cultural de que se ocupava, do livro ao direito do autor, desse ao patrimônio histórico e, finalmente, ao "direito cultural".

Palavras-chave: memória; Estado; direito cultural.
\end{abstract}

$\mathrm{N}$ ão é preciso haver lido Norbert Elias para nos darmos conta da complexidade da cultura como objeto. Qualquer pessoa, mesmo intuitivamente, experimenta uma sorte de insaciedade quando se relaciona com o que convencionalmente se chama bem cultu$\mathrm{ral}$. Sabemos da precariedade do vínculo que com ele estabelecemos - por exemplo, o vínculo fugidio, num espaço cerimonial de museu - ou a parcialidade que preside o seu estar ali, parte que é de um processo em que o produtor fica subsumido na celebração que sua obra enseja. Podemos ainda nos perguntar: se a economia institui o mercado no jogo cego das trocas elevando-o à instância "autônoma" da vida social, qual o movimento equivalente que põe a cultura? Para a maior parte dos antropólogos que vê a vida social como uma totalidade, essas questões parecem mera mistificação, pois o imbricamento concreto entre as várias esferas da atividade humana mostra cultura, economia, religião, etc. incrustadas (embedded $)^{1}$ umas nas outras.

A multiplicidade de objetos culturais, hoje dados ao consumo e fruição em redes de significações de amplo acesso, é talvez a característica mais instigante dos tempos ultramodernos. Dificilmente conseguimos analisar essa constelação sem recorrermos a analogias imperfeitas como o mercado - sim, imperfeitas porque se o "bem cultural" fosse mero suporte da mercadoria (seu valor de uso) não haveria por que distingui-lo com tanta atenção.
Quando a economia política surgiu para "explicar" o mercado, ele já tinha uma densidade e uma tessitura tal que impedia o distanciamento em relação ao fetiche da mercadoria, levando de roldão a jovem ciência. Analogamente, quando o "bem cultural" se institui como uma categoria de pensamento, o seu estatuto já é de coisa despregada da vida, de algo que precisa reencontrar o seu lugar como objeto estruturante do mundo da produção. Por sua vez, ao Estado, querendo se situar para além da administração das coisas, parece natural que se ocupe do refinamento do espírito humano, debruçando-se sobre a cultura e a produção simbólica que a expressa.

A cultura autonomizada é algo que aparece apartado do mercado, irredutível a ele e, muitas vezes, antagônico. Ao menos na tradição ocidental européia, à qual gostosamente queremos nos filiar, arrastar a cultura ao mercado pode ser sinônimo de conspurcação. Que os norte-americanos tenham instituído no mercado a sua cultura é algo que não os recomenda... diz o corolário do nosso teorema europeizado.

Ora, só o Estado pode proteger a cultura das forças corruptoras do mercado, mas se ele se põe a administrar a cultura entre os cidadãos - ele que é o promotor da igualdade - é porque na sociedade, por razões várias (nascimento, educação formal, renda, filiação étnica, etc.), a cultura é um domínio "defeituoso" que se distribui de forma desigual entre detentores dos mesmos direitos. Nesse par- 
ticular, o acesso à cultura, suprimindo as diferenças inerentes às desigualdades, passa a depender do sistema educacional e de outros mecanismos públicos compensatórios. Mas a cultura, no seu espectro mais amplo, resiste a reducionismos: transborda a escola, ganha as ruas, os teatros, os museus, a ópera, os recônditos onde se diverte o proletariado, renovando sempre as sensações de inclusão/ exclusão, de pertinência e estranhamento. Por isso é que, para além da "administração das coisas", precisa o Estado situar-se no terreno movediço dos conteúdos simbólicos da vida e escolher uma perspectiva de ação.

\section{O ESTADO COMO DEFINIDOR DA CULTURA}

A primeira intervenção do Estado na esfera cultural está centrada precisamente na definição do que a sociedade deva reconhecer como cultura. Na tradição ocidental pósiluminista, o Estado aparece de modo crescente como um agente do processo cultural: ele produz cultura ou administra sua produção e difusão pelos agentes privados. $\mathrm{Na}$ verdade ele fixa e define para a sociedade, em cada momento histórico, o que se reconhece como cultura. Isso é verdade especialmente a partir do romantismo do século XIX, quando as idéias de nação e povo adquirem um claro conteúdo simbólico, capaz de produzir instituições a elas devotadas. Paralelamente, por procedimentos de caráter educacional, o Estado propicia a via de acesso a certos domínios culturais que não são gerais. Assim é, por exemplo, com a alta cultura que, para sua fruição plena, exige o cidadão formado de modo específico (exemplos: a música clássica, os estilos pictóricos, arquitetônicos, etc.). Por fim, acaba o Estado destacando do conjunto indeterminado da cultura da sociedade um subconjunto que deve ser tomado como patrimônio de todos e o submete a políticas específicas de produção, difusão, consumo, proteção. Como tende a só reconhecer traços culturais consolidados, ele sempre está em descompasso ou defasagem com a produção cultural do momento e sua ação consiste justamente em administrar este descompasso preparando a passagem do momento inicial para o seguinte.

É fácil perceber que entre nós, brasileiros, muitas vezes o Estado "fabricou" o mercado, manipulou a economia, mas não é tão simples se dar conta de como ele inventou a cultura. Visto de uma perspectiva genérica, a cristalização da cultura em instituições se deu no processo de independência e formação do Estado brasileiro, logo na fase que uma historiadora chamou de "interiorização da metrópole", ${ }^{2}$ e pode ter como marco inicial a Bibliote- ca Nacional, formada por D. João VI a partir de livros trazidos pela Corte; depois, com a Independência e a organização da imprensa livre, ela seguiu sendo a instituição, por excelência, da cultura.

Se acompanhamos esse processo por meio dos textos constitucionais, vemos que na Constituição Política do Império do Brasil (1824), em seu artigo 179, aparece a única referência ao que hoje chamamos cultura: "Todos podem communicar os seus pensamentos, por palavras, escriptos e publical-os pela Imprensa, sem dependencia de censura; contanto que hajam de responder pelos abusos que commetterem no exercício deste Direito". De fato, a maior conquista intelectual de então era a liberdade de expressão, tão oprimida sob o estatuto colonial a ponto de impedir mesmo a atividade editorial em território brasileiro. Já na primeira Constituição da República (1891) à ênfase na liberdade de expressão somava-se a garantia do direito do autor: "Aos autores de obras litterarias e artísticas é garantido o direito exclusivo de reproduzi-las pela imprensa ou por qualquer outro processo mecanico. Os herdeiros dos autores gozarão desse direito pelo tempo que a lei determinar" ( $\$ 26$, seção Declaração dos Direitos).

Só nos anos 30 do século XX deixa a cultura, na definição estatal, de gravitar exclusivamente em torno do livro. Embora garantindo também o direito do autor, estende-se a responsabilidade pública sobre a cultura ao dizer, no artigo 10 da Constituição de 1934, que compete à União e aos Estados "proteger as bellezas naturaes e os monumentos de valor histórico, ou artístico, podendo impedir a evasão de obras de arte", e acresce, no artigo 148, que "Cabe à União, aos Estados e aos Municípios favorecer e animar o desenvolvimento das sciencias, das artes, das letras e da cultura em geral, proteger os objectos de interesse histórico e o patrimônio artístico do paiz, bem como prestar assistência ao trabalhador intellectual".

$\mathrm{Na}$ Constituição de 1937, no capítulo que trata da Educação e da Cultura, lê-se:

“Art. 128 - A arte, a ciência e o seu ensino são livres à iniciativa individual e à de associações ou pessoas coletivas, públicas e particulares. É dever do Estado contribuir, direta e indiretamente, para o estímulo e desenvolvimento de umas e de outro, favorecendo ou fundando instituições artísticas, científicas e de ensino.

Art. 134 - Os monumentos históricos, artísticos e naturais, assim como as paisagens ou os locais particularmente dotados pela natureza, gozam de pro- 
teção e dos cuidados especiais da Nação, dos Estados e dos Municípios. Os atentados contra eles cometidos serão equiparados aos cometidos contra o patrimônio nacional".

Finalmente, parece ser na Constituição de 1946 que chegamos ao embrião da definição moderna de cultura adotada pelo Estado brasileiro:

"Art. 141 - A Constituição assegura aos brasileiros e aos estrangeiros residentes no país a inviolabilidade dos direitos concernentes à vida, à liberdade, à segurança individual e à propriedade, nos termos seguintes:

$\S 19$ - Aos autores de obras literárias, artísticas ou científicas pertence o direito exclusivo de reproduzi-las. Os herdeiros dos autores gozarão desse direito pelo tempo que a lei fixar.

Art. 173 - As ciências, as letras e as artes são livres.

Art. 174 - O amparo à cultura é dever do Estado. Parágrafo Único - A lei promoverá a criação de institutos de pesquisas, de preferência junto aos estabelecimentos de ensino superior.

Art. 175 - As obras, monumentos e documentos de valor histórico e artístico, bem como os monumentos naturais, as paisagens e os locais dotados de particular beleza ficam sob a proteção do poder público".

Esse percurso por textos constitucionais mostra a ampliação do foco de atenção do Estado numa sociedade que, ao se tornar mais complexa, requer novos conteúdos simbólicos para expressar a nacionalidade. Evidentemente as constituições fixam meras relações abstratas com os objetos culturais, mas revelam com clareza o que o poder "vê" como sendo cultura e, em nosso caso, como em pouco mais de um século deixou de mirar apenas o livro para olhar seu autor e, mais tarde, a história cristalizada nas variadas obras humanas engendradas por brasileiros.

Se ultrapassarmos o plano meramente legal, veremos que no Império o passo mais importante em direção ao envolvimento do poder com a cultura foi a formação do Instituto Histórico e Geográfico Brasileiro, expressamente incumbido de definir a "história nossa", a "geografia nossa" e a "cultura nossa" de modo a permitir o reconhecimento pelos brasileiros dos conteúdos simbólicos da nação, iluminados pela visão erudita do imperador e das classes proprietárias. Essa instituição organizou-se nacionalmente pela fundação de congêneres nas províncias e acolheu inscrições de sócios sempre com o fito de armar uma rede capilar e capaz de reunir documentos e registros de fatos que poderiam ser celebrados como "nossos". A consolidação dessa visão se deu na monumental obra de Francisco Adolpho de Varnhagen (1948), significativamente intitulada Historia geral do Brasil antes da independência de Portugal. A visão romântica que presidiu a construção desse edifício historiográfico pôs em relevo, entre outros conteúdos, as culturas indígenas (especialmente línguas e costumes) e a vertente colonizadora (européia), silenciando sobre o negro. A par com essa atividade, as artes plásticas e as ciências também foram submetidas a estratégias de "interiorização" e começaram a gerar instituições específicas.

Já num outro momento, em fins do Império, mas ainda relacionado com o contexto romântico - mesmo que contaminado por idéias novas de caráter evolucionista -, um novo corpo de conhecimentos passa a ser agregado: ofolclore. Trata-se do registro de produções "espontâneas" do "povo" consubstanciado, por exemplo, na obra de Silvio Romero - autor fortemente influenciado pelos culturalistas alemães. Na mesma vertente, uma nova historiografia também começa a se desenhar, focando a "história do povo", e que tem sua expressão maior no historiador cearense Capistrano de Abreu. Salvo engano, as duas primeiras décadas da República não trazem inovações sob esse aspecto.

Já nos anos 30 assiste-se a uma verdadeira revolução na relação do poder público com a cultura, lançando-se as bases da atividade cultural moderna do Estado. As grandes contribuições advêm de dois processos paralelos: a redefinição de conteúdos culturais; a institucionalização de formas modernas de administração cultural. Quanto à redefinição dos conteúdos culturais da nação tem papel crucial a obra de Gilberto Freyre, de um lado, e, de outro, dos modernistas de 22. Eles cristalizam a idéia de uma matriz tripartite de contribuições para a formação do povo brasileiro: os brancos (portugueses), os índios e os negros. Além disso, definiram um estilo como nosso: o "barroco brasileiro". No tocante à institucionalização das formas de administração da cultura é o governo Vargas, no período ditatorial, que promove a mais importante transformação mediante a ação de Gustavo Capanema à frente do Ministério de Educação e Saúde. Data dessa época a instituição do princípio do tombamento de bens históricos integrantes do patrimônio cultural nacional e a própria formação do embrião do que hoje vem a ser o Iphan.

De fato, coube a Mário de Andrade, autor do projeto de decreto que criou o Sphan, definir a cultura para o 
moderno Estado brasileiro. Essa definição operacional (consubstanciada no Decreto-Lei ${ }^{\circ} 25$, de 30 de novembro de 1937) estabelece que: a) passa a existir um patrimônio histórico e artístico nacional, composto por um conjunto de bens móveis e imóveis existentes no país; b) os bens que integram essa categoria são os inscritos separada ou agrupadamente em quatro Livros de Tombo, a saber: Livro do Tombo Arqueológico, Etnográfico e Paisagístico; Livro do Tombo Histórico; Livro do Tombo das Belas Artes; Livro do Tombo das Artes Aplicadas. Estabelece ainda que o tombamento pode ser voluntário ou compulsório e os bens tombados, mesmo que de particulares, passam a ter restrições no direito de propriedade. Os livros de tombo concebidos por Mário definem, portanto, o estoque de bens culturais de propriedade ou administrados pelo poder público como signos da nacionalidade. $^{3}$

Antes desse momento, a relação do Estado com a cultura restringia-se à garantia dos direitos de autor e a uma ênfase de conteúdo dentro do processo educacional ("instrução pública", chamava-se...). A estreita associação entre cultura e educação não exigia um aparato estatal diferenciado para administrar a cultura.

Como observou Jurema Machado, ao contrário da legislação ambiental que lhe pode servir de parâmetro - visto tratar também da preservação do bem público e que veio como resposta aos movimentos da sociedade -, a legislação do patrimônio não correspondia a uma necessidade socialmente reconhecida; ao contrário, buscava criar a necessidade a partir da crença da elite de que a cultura era fundamental à formação dos cidadãos. "Num país que mal começava a se urbanizar, essa elite, representada por um grupo de intelectuais da vanguarda modernista, se propôs a ser intérprete e porta-voz de uma sociedade ainda desorganizada, para "escrever, simultaneamente, a árvore genealógica e o mapa astral do país" (Cavalcanti, 1993:23). Assim, "fundado exclusivamente na avaliação daquilo que se entendia como qualidade arquitetônica e afastado de uma visão histórica mais abrangente, o Iphan realizou intervenções homogeneizadoras com o objetivo de conferir unidade estilística a edifícios ou a conjuntos urbanos que, certamente, jamais a tiveram. Em Ouro Preto, por exemplo, onde a tipologia arquitetônica correspondente ao período colonial predominava quantitativamente no conjunto urbano, mas não era exclusiva, exemplares do ecletismo - testemunho importante de um esforço de modernização empreendido pela cidade na virada do século - foram mascarados por beirais em cachorrada e apa- gados com pintura cinza insossa. A adoção generalizada do branco nas fachadas também serviu ao objetivo de homogeneização, uma vez que representou, na melhor das hipóteses, a eleição do padrão de uma determinada época e que a sua escolha foi fortemente induzida por uma opção estética" (Machado, 1999).

Sob o Estado Novo e mesmo após a sua queda, com a formação dos mecanismos de administração desse estoque patrimonial, o Estado brasileiro passa a ter como atribuições definidas em lei a preservação do patrimônio cultural, a facilitação do acesso a ele (fruição) e o fomento à produção cultural. Esse conjunto de obrigações de fazer manteve-se ainda associado aos processos educacionais, o que emprestava à administração da cultura um caráter formador e pedagógico até o advento da Constituição de 1988, quando as instituições culturais que encarnam essas obrigações de fazer foram consolidadas como especializações administrativas.

Assim, vistas por sua natureza, temos hoje uma variedade de instituições: bibliotecas; museus; arquivos; espaços públicos, especializados ou multifuncionais, para espetáculos; entidades de promoção, de formação, de divulgação e de fomento; entidades de registro de direitos autorais, etc. Já sob influência do Decreto-Lei 200, editado à época da ditadura militar, surgiram as fundações, autarquias e empresas públicas direcionadas para a cultura. Todas essas entidades, ou o que delas restou após inúmeros processos de reforma do aparelho do Estado, estão hoje congregadas no MinC e operam uma série de sistemas voltados para a cultura, sendo os principais deles: ${ }^{4}$

- sistema de bibliotecas (tendo como "cabeça" a Biblioteca Nacional);

- sistema de registro de direitos sobre propriedade intelectual (livros);

- sistema MinC, abrangendo a definição de políticas culturais, seu fomento e difusão.

Pode-se dizer, portanto, que ao longo dos séculos XIX e XX o Estado brasileiro definiu para a sociedade o que reconhece como cultura, instituiu-a legalmente e organizou em torno dela uma complexa e variada máquina administrativa. Nesse processo, criou uma burocracia interessada na reprodução desse aparato e, por várias políticas, solidarizou artistas e intelectuais com os parâmetros que adotou para essa atividade pública. Burocratas e intelectuais gravitando em redor dos recursos públicos constituíram o "povo da cultura" (por oposição à "cultura do 
povo" - essa só existente nos tratados de folclore ou no remoto sertão, onde o Estado ainda hoje pouco chega).

\section{A ÊNFASE MODERNA NA PERMANÊNCIA E A DIFICULDADE DA INOVAÇÃO}

Após o rápido percurso de encarregos do Estado brasileiro perante a cultura, vale a pena nos determos mais no texto constitucional em vigor. Ali está definido que “o Estado garantirá a todos o pleno exercício dos direitos culturais e acesso às fontes de cultura nacional, e apoiará e incentivará a valorização e a difusão das manifestações culturais" (Artigo 215). Além da inovação imprecisa dos "direitos culturais", a Constituição se refere à "cultura nacional" como algo constituído e de sentido inequívoco. Colocou-se assim o Estado na contramão do processo de internacionalização dos conteúdos simbólicos que, graças às modernas tecnologias, desconhecem fronteiras nacionais. Esse caráter eminentemente conservador que a ação pública cultiva fica ainda mais claro quando a Constituição diz que "constituem patrimônio cultural brasileiro os bens de natureza material e imaterial, tomados individualmente ou em conjunto, portadores de referência à identidade, à ação, à memória dos diferentes grupos formadores da sociedade brasileira" (Artigo 216).

A obrigação de manter e conservar as "identidades" dos diversos grupos que formam a sociedade brasileira desenha um espectro bastante amplo. Inclui no seu foco as formas de expressão; os modos de criar, fazer e viver; as criações científicas, artísticas e tecnológicas; as obras, objetos, documentos, edificações e espaços destinados a manifestações culturais; os conjuntos urbanos e sítios de valor histórico, paisagístico, artístico, arqueológico, paleontológico, ecológico e científico. No entanto, a obrigação específica do Estado nesse particular é restrita a proteger esse patrimônio por meio de "inventários, registros, vigilância, tombamento e desapropriação, e de outras formas de acautelamento e preservação" (Artigo 216 $\S 1)$. No mais, deve ele associar-se à comunidade para garantir a difusão, o acesso, a produção, etc.

Pode-se dizer que o programa enunciado para a cultura é bastante simples e possui um foco preciso. Se na época de Mário de Andrade isso significou uma profunda inovação, constituindo mesmo o triunfo dos intelectuais modernos sobre as correntes conservadoras da cultura, ${ }^{5}$ a sua reprodução quase que ipsis literis no novo texto constitucional possui um sentido passadista bastante óbvio.
A idéia de patrimônio é, em nossa sociedade, associada a valores imobilizados. O "tombamento" tem o sentido de cristalização no tempo. ${ }^{6}$ Esse estoque de bens, colocado fora do mercado e gerido pelo Estado, deve produzir a identidade dos cidadãos. Mas não é só nesse domínio que a obrigação do Estado se define por oposição ao mercado. Há uma publicação do Ministério da Cultura (s.d.) intitulada Calendário de eventos culturais em cujo prefácio, assinado pelo Ministro, lê-se: "Estimular sem intervir é talvez o maior desafio para uma política cultural democrática. Nessa perspectiva se incluem medidas visando à criação de mecanismos de incentivo ao investimento privado; ao apoio a criadores iniciantes e a manifestações culturais significativas, mas de menor interesse comercial; à difusão e ao consumo de cultura". O calendário, especificamente, é uma coleção de informações que visa facilitar "o acesso do público à cultura". Qual é, contudo, essa cultura inventariada, espontânea, à qual o público deve acorrer?

Trata-se de um elenco de mais de dois mil eventos culturais que se repetem anualmente e que estão classificados segundo a Tabela 1. A chamada "cultura popular", o segmento mais expressivo, está constituído conforme a Tabela 2.

TABELA 1

Eventos Culturais, segundo Segmento Brasil - 1997-98

Em porcentagem

\begin{tabular}{lc}
\hline Segmento & Distribuição \\
\hline Total & 100,0 \\
Artes Cênicas & 7,0 \\
Artes Visuais & 7,0 \\
Cinema/Vídeo & 2,0 \\
Música & 15,0 \\
Livros, Literatura & 4,0 \\
Cultura Popular & 60,0 \\
Dimensão Etnocultural & 4,0 \\
\hline
\end{tabular}

Fonte: Ministério da Cultura, s.d.

TABELA 2

Distribuição da Cultura Popular

Brasil - 1997-98

\begin{tabular}{lc}
\hline Cultura Popular & Números Absolutos \\
\hline Folclore & 117 \\
Artesanato & 33 \\
Manifestações Religiosas & 159 \\
Carnaval & 62 \\
Gastronomia & 16 \\
Festas Cívicas & 67 \\
Outras & 15 \\
\hline
\end{tabular}

Fonte: Ministério da Cultura, s.d. 
É perceptível que escapam à visualização do Estado, quando ele se volta para a cultura do seu povo, as dimensões modernas da cultura de massa (o design, as linguagens multimídia, a música kitsch, etc.). Por outro lado, ocupam o cerne da "cultura popular" os eventos classificados como "folclore", a religiosidade e as festas cívicas. Mas não só para as atividades (eventos) tradicionais dirige-se o esforço do Estado para preservar a cultura. Também no capítulo patrimonial é notável a concentração de bens, móveis e imóveis, de origem religiosa que compõem o acervo tombado. A República laica tem, no Brasil, um forte viés religioso (católico).

Se o Estado dá suporte aos aparatos material e imaterial da cultura em seus segmentos mais tradicionais, assumindo assim um papel conservador, de outra forma busca inovar pelo recurso ao mercado. Durante os anos 90 a busca de um "modelo de financiamento da cultura" foi a preocupação central do poder público federal. Isso se deveu não apenas à institucionalização da função "cultura" no Estado, levando à criação do Ministério da Cultura e à necessidade de recursos para manter seu aparato burocrático, mas também à crescente demanda dos setores médios urbanos por produtos de consumo identificados como "culturais", levando à expansão das áreas que o Estado precisaria atuar para manter minimamente seu papel no processo de geração de "identidades nacionais". A indústria cultural explodiu e seus números tornaram-se cada vez mais expressivos. Na rabeira dessa demanda objetiva o Estado tratou de se posicionar, definindo novos vínculos com a produção e o consumo de cultura.

No novo modelo de financiamento, em que o recurso ao mercado tornou-se peça-chave para praticamente dobrar os investimentos em cultura, o que se vislumbra é uma submissão crescente ao gosto médio do empresariado nesse sentido, temos a afirmação de uma cultura de massa, pasteurizada, espetaculosa e em oposição à vertente patrimonialista e passadista que marca as ações diretas da administração federal diante da cultura, além de uma crescente alienação das políticas culturais que decorre da inclusão das grandes corporações no processo de decisão sobre investimentos cada vez mais vultosos.

\section{MAZELAS DO PRESENTE}

O panorama que se vê hoje, tendo o Estado brasileiro no centro da política cultural, é bastante singular. Por um lado uma cultura multiétnica, multinacional, sem um único pólo aglutinador ou uma tradição, mas com vários pó- los geradores de conteúdo, que se organiza em redes de significações sem fronteiras e abarca a todos. Nessa cultura está subsumida a grande parcela dos jovens, especialmente dos grandes centros urbanos, independentemente da extração social, nível de formação educacional. As redes de significações internacionalizadas são suficientemente abertas e diversificadas para abarcar uma infinidade de situações concretas e se renovar continuadamente. Por outro lado, temos uma cultura medíocre, tendendo a levar a mercantilização aos produtos mais variados, voltada prioritariamente para o consumo das elites e dos seus satélites sociais - cultura essa apoiada em fundos públicos geridos pelas grandes corporações do mercado. Numa terceira posição, como cidadela da tradição, o Estado, garantidor do patrimônio tombado, promotor do espontâneo, inventariante da "cultura nossa" garantida com o dinheiro de todos.

É evidente que a posição do Estado nesse contexto é determinada por fatores diferentes dos que levaram à criação da moderna política cultural por Mário de Andrade. O patrimônio, hoje, é bastante denso e espesso, caminhando para um engrossamento cada vez maior na medida em que a própria noção que o preside transborda dos limites do barroco para incorporar - no plano da arquitetura - o ecletismo e o modernismo como fontes de identidade estilística. Também a chamada "cultura imaterial" passou a ser identificada e "protegida" pelo Estado por recente decreto, ${ }^{7}$ sendo que cada manifestação coletada receberá o título de "Patrimônio Cultural do Brasil" concedido pelo Estado. Esse adensamento talvez seja o caminho para se compreender o verdadeiro sentido do termo "direitos culturais", formulado abstratamente na Constituição de 1988.

"Direitos culturais" abrem a via da interpretação dos governos, podendo variar no tempo conforme seja a ênfase dada ao aspecto da produção, da difusão ou do consumo cultural ou, ainda, a identificação e privilégio desta ou daquela arte sobre as demais. Mas "direitos culturais" são também de natureza simbólica e, como tal, o Estado busca concretizá-los a cada momento, por meio das várias políticas que implementa. A interpretação que hoje se atribui a eles é, inequivocamente, o direito à memória. A memória de um país que fomos e já não somos; memória administrada pelo Estado seja na identificação e preservação de seus vestígios (materiais ou imateriais), seja no reconhecimento da cultura "popular e espontânea" numa época em que a cultura pós-moderna é toda ela produzida e planejada por vigorosas estruturas industrial e comercial. Ser brasileiro é ter o direito ao passado imaginário, à 
memória dos tempos iluminada pela merencória luz do Estado. Ser brasileiro é, num certo sentido, ser "fazendeiro do ar" no latifúndio estatal.

Ao trabalhar a memória, muitas vezes o Estado sofre a tentação de reeditar as mitologias passadistas sobre a sociedade brasileira. Tome-se, como exemplo, a ênfase que a Constituição de 1988 atribui às tradições afro-brasileiras e indígenas. A incorporação dos quilombos ao patrimônio histórico reflete uma reivindicação da militância negra nos anos da Constituinte e também um novo tratamento da matriz mitológica da convergência das três raças formadoras da nacionalidade, conforme definido pelos modernistas dos anos 20 e pela obra de Gilberto Freyre. Naquele ideal, as "raças" se dissolveriam pela miscigenação, criando o tipo brasileiro no concerto das nações. Isso significou excluir do inventário das contribuições étnicas aquelas advindas de outras vertentes européias que não os portugueses (ou mesmo orientais) como os judeus, os italianos, os árabes, os chineses, etc., quando da observação do passado colonial ou do século XIX.

Hoje, com a recém-descoberta sinagoga do Recife, inicia-se a "correção" desse estereótipo. Por outro lado, o ideal moderno de democracia é multicultural e multiétnico, como uma espécie de "biodiversidade social". Nos Estados Unidos, sociedade em que esse conceito nasceu, o indivíduo é anterior ao Estado e não uma criação sua, como na tradição francesa à qual nos filiamos; o cidadão norteamericano pertence antes a um grupo particular e, só depois, à coletividade norte-americana: são afro-americanos, italo-americanos, etc. Por essa ótica, mais do que a presença negra no passado, trata-se sempre de situá-la no presente, em suas múltiplas manifestações, garantindo sua expressão ali onde as forças cegas do mercado ameaçam sua existência.

Entre nós, inversamente, há na valorização patrimonial dos quilombos um duplo sentido: uma valorização do negro na matriz mitológica da origem do povo brasileiro e, ainda, uma armadilha passadista para a militância negra em busca da afirmação presente dos direitos dessa enorme massa de brasileiros excluídos de amplas esferas da vida societária.

Apesar dessas armadilhas, é inegável que o direito à memória funciona como um dique à pasteurização cultural em escala planetária hoje promovida em ritmo vertiginoso pela globalização dos processos de produção e consumo. À hollywoodinização do cinema, à disneyzação da infância, à sonnyzação da música contrapõe o Estado uma memória de identidade indissoluta. Ainda que passadista, arcaizante, essa memória é matéria-prima para muitos produtos culturais modernos. O "maracatu atômico" do tropicalismo talvez seja a metáfora mais promissora dessa releitura do passado, reinscrevendo-o no presente com vigor inequívoco.

Resta saber qual o valor de tudo isso na construção da sociedade moderna e democrática. Até mesmo por vícios de formação não podemos deixar de ceder à tentação de generalizações que, felizmente, os historiadores estarão aí para corrigir, se forem demasiado imprecisas. Mas provavelmente a cultura, vista como direito à tradição, passará a ter um papel determinante no processo histórico que vivemos. Há uma década, o historiador Charles Tilly encantou o mundo pensante europeu com seu trabalho intitulado Coercion, capital and european states. A.D. 990-1990. No prefácio à edição espanhola do seu livro, dizia que "em sua grande maioria, a Nação-Estado é um mito. Os grandes Estados europeus perpetuaram o mito, $\mathrm{e}$ em certas ocasiões o aplicaram à realidade, instituindo a educação centralizada, estabelecendo códigos legais, impondo exércitos unificados, criando igrejas oficiais e suprimindo línguas minoritárias. (Recordemos o antigo ditado de que um idioma é um dialeto que tem exército próprio.) Neste sentido, os soberanos europeus chegaram a criar certo grau de uniformidade entre as heterogêneas populações que conquistaram ou herdaram. E, apesar de tudo, os bretões e alsacianos sobreviveram ou reviveram na França, os gauleses e escoceses na Grã-Bretanha, os bascos e catalães na Espanha" (Tilly, 1992:17). Nos Estados de formação tardia, como a Itália, bem sabemos a importância que tiveram a língua, a cultura e a história para formar a convergência política que é o nacional.

No século XIX a língua e o folclore desempenharam papel estratégico como critério de nacionalidade, a par com o território. O romantismo é o movimento intelectual que dota o Estado novecentista do substrato simbólico de que necessita para cimentar um povo. Bem sabemos o quanto José de Alencar, Carlos Gomes ou Gonçalves Dias se esforçaram, entre nós, para encontrar a brasilidade. ${ }^{8}$ Pois bem, na pós-modernidade, território e língua perdem sentido como signos distintivos e, da mesma forma, o folclore, de vez que o mundo se transformou, aproveitando a expressão de Hobsbawm, numa espécie de "presente contínuo" em que a origem não confere cidadania no tempo. O intelectual pós-moderno é "desenraizado"; universal, e se sente "desatualizado" quando olha para dentro de seu país. ${ }^{9}$ Resta pois a memória como aspecto distintivo, a memória como matéria de culto para um Estado que se 
contrapõe ao que vislumbra como destino universal dos povos. Resta-lhe fomentar a lembrança dos que, como Carlos Drummond de Andrade em Retrato de Família, se situam para além do esquecimento com estranho sentimento de pertinência:

(...) Já não distingo os que foram/ dos que restaram. Percebo apenas/ a estranha idéia de família/ viajando através da carne.

\section{NOTAS}

E-mail do autor: cadoria2@uol.com.br

Texto preparado em maio de 2001.

1. Esse conceito é do economista Karl Polannyi.

2. Expressão de Maria Odila da Silva Dias.

3. É interessante registrar aqui o sentido que Márcio Souza atribui à periodização adotada: "Como que para contrariar os mitos da falta de políticas e da descontinuidade, somente nos últimos 150 anos o país experimentou dois exemplos modelares de política cultural que perduraram o suficiente para gerar conseqüências e imprimir rotinas. O primeiro dos programas, que vai de 1808 a 1929, foi capaz de promover investimentos no campo cultural em igualdade de condições com os demais segmentos da economia, com o objetivo imediato de melhorar o nível social de uma colônia atrasada, mas fez tanto sucesso que acabou por durar mais de um século (...). O segundo programa, que pode ser datado de 1937 e segue até os dias de hoje (...), foi concebido de forma mais consciente e com claros objetivos hegemônicos que privilegiavam a cultura ibérica. Uma política acirradamente conservadora, que desejava fabricar um passado e moldar um futuro, ancorando-se num ultramodernismo extremamente aderente ao desejo de inventar uma nação e forjar um povo. Este último caso, que ainda nos assalta, fincou raízes profundas nas consciências e sintetizou um conjunto de doutrinas aceitas tacitamente como essências da nacionalidade, que vai desde as formas de retórica literária à mitologia da tolerância racial até a estética do verde-amarelismo e a fabricação do passado através de uma ideologia de patrimônio histórico a ser preservado" (Souza, 2000:16).
4. Por razões anacrônicas, o Arquivo Nacional mantem-se, hoje, na Presidência da República e, com ele, o Sistema Nacional de Arquivos.

5. Esse aspecto foi analisado em ensaio publicado em livro recém-editado pela Caixa Econômica Federal, intitulado Histórias em pedra e cal (CEF, 2000).

6. A primeira lei específica de preservação de monumentos foi criada em 1819 e publicada como édito pontifício pelo Cardeal Pacca, protegendo o patrimônio nos Estados papais.

7. Trata-se do Decreto-Lei $n^{\circ} 3.551$, de 4 de agosto de 2000, que institui o Registro de Bens Culturais de Natureza Imaterial que constituem patrimônio cultural brasileiro, cria o Programa Nacional do Patrimônio Imaterial e dá outras providências.

8. Ver, ainda, a respeito desse tema, mas para um período mais recente, o artigo de Dória (1991)

9. A idéia de "atualização" é bem diferente daquela dos intelectuais que esperam os navios trazerem nos seus porões as últimas modas da Europa. A atualização pós-moderna não é um mero aggiornamento, pois se trata de um atributo do ser, como se ele fosse portador da história toda.

\section{REFERÊNCIAS BIBLIOGRÁFICAS}

CAVALCANTI, L. Os modernistas na repartição. Rio de Janeiro, 1993.

CEF - Caixa Econômica Federal. Histórias em pedra e cal. Brasília, 2000.

DÓRIA, C.A. "O intelectual em seu labirinto". In: . Ensaios Enveredados. São Paulo, Siciliano, 1991.

MACHADO, J. A preservação do patrimônio cultural a partir do município: perspectivas e estratégias. Curitiba, mar. 1999, mimeo.

MINISTÉRIO DA CULTURA. Calendário de eventos culturais - Brasil 1997-1998. Brasília, s.d.

SOUZA, M. "Fascínio e repulsa: Estado, cultura e sociedade no Brasil". Cadernos do Nosso Tempo - nova série. Rio de Janeiro, Funarte, 2000.

TILLY, C. Coerción, capital y los estados europeus. 990-1990. Madrid, Alianza Editorial, 1992.

VARNHAGEN, F.A. de. História geral do Brasil - antes da sua separação e independência de Portugal. $4^{\mathrm{a}}$ ed. São Paulo, Companhia Melhoramentos, 1948. 